\title{
Sexual Violence and Associated Factors Among Female Students of Preparatory Schools in Modjo and Bishoftu Towns of East Showa Zone, Oromia State, Ethiopia
}

\author{
Suraphel Fekadu Mekonnen, Sileshi Garoma Abeya", Ebrahim Mohammed Gebaba \\ Department of Public Health, Adama Hospital Medical College, Department of Public Health, Adama, Ethiopia \\ Email address: \\ surexkoo@gmail.com (S. F. Mekonnen), garomaabe@gmail.com (S. G. Abeya), ebrahim.m805@gmail.com (E. M. Gebaba) \\ ${ }^{*}$ Corresponding author
}

\section{To cite this article:}

Suraphel Fekadu Mekonnen, Sileshi Garoma Abeya, Ebrahim Mohammed Gebaba. Sexual Violence and Associated Factors Among Female Students of Preparatory Schools in Modjo and Bishoftu Towns of East Showa Zone, Oromia State, Ethiopia. Rehabilitation Science.

Vol. 4, No. 3, 2019, pp. 44-53. doi: 10.11648/j.rs.20190403.12

Received: September 30, 2019; Accepted: October 30, 2019; Published: November 7, 2019

\begin{abstract}
Worldwide, the range and magnitude of sexual violence have tremendous negative impact for both the individual and society. This study was conducted to assess the prevalence of sexual violence and associated factors among female students of preparatory schools in Modjo and Bishoftu towns from September 1 to December 30, 2018. Institutional based cross-sectional study design was conducted. A sample of 323 female students was randomly taken from four preparatory schools. The collected data was entered into Epi Info 7 and exported to SPSS version 20 for analysis. Four FGD's were conducted targeting community representatives and the required sample size was determined based on the saturation of information. The study showed a prevalence of $74 \%$ of sexual violence in the study area. Iin the final model, age group of 17 18 (AOR: 6.39; 95\% of CI: 3.64, 63.12), teacher perpetrator (AOR, 0.37; 95\%CI: 0.01, 0.13) and knowledge of ever encountered a person with sexual violence (AOR, 1.21; 95\%CI: 1.13, 4.59) was found significant $(\mathrm{P}<0.05)$. A significant proportion $(74 \%)$ of respondent's experienced sexual violence. Unwelcome touching and ever had sexual intercourse without their consents were the most common types of sexual violence in the study area. Lower age, perpetrator category and knowledge towards sexual violence were associated with sexual violence. There is a need to have systematic and strategic intervention using school based programs to address the full context of female students and others young girl lives, including society, behavioral and environmental factors leading to the problem of sexual violence.
\end{abstract}

Keywords: Sexual Violence, Unwelcome Touching, Verbal Joking, Forceful Sexual Intercourse

\section{Introduction}

Sexual violence is an extreme restriction of the sexual and reproductive autonomy of women [1]. Although it is largely hidden by the victims, it was estimated that 12 million people around the world face sexual violence every year [2]. Young people are the most frequent victims of sexual violence and it is generally thought that $12 \%$ to $25 \%$ of girls and $8 \%$ to $10 \%$ of boys less than 18 years of age suffer from sexual violence [3].

Sexual violence among female students has become a growing concern in sub-Saharan Africa [3]. According to the World Health Organization (WHO), about 150 million female students had experience of sexual violence [4]. In parts of South Africa and Tanzania, up to a third of female students reported that their first sexual experience was forced [5]. A study in Cape Town, South Africa on female students reported $11 \%$ of rape and $72 \%$ forced sex, while in other areas of South Africa, a survey confirmed alarmingly high incidence, between 28 and $30 \%$, of forced sexual initiation among female students [5-7].

In few studies conducted in Ethiopia provided some insight into the magnitude of the problem but lack thoroughness and depth [8]. Study done on sexual violence and associated factors among high school female students in Harar town of Eastern Ethiopia showed the prevalence of 
$25 \%$ among female high school students [8]. These students used addictive drugs like alcohol (18\%), Khat and Shisha (7.2) [8]. Female high school students who reported high risk of sexual violence faced unwelcome touching of body part (18.3\%) and forced sexual attempt (16.8\%) [9]. In spite of having boyfriend, the violation is associated with alcohol consumption [9]. Another study conducted among high school students in Addis Ababa and Western Showa revealed prevalence of performed rape at 5\%, attempted rape of $10 \%$, and harassments of $74.3 \%$ [9]. Another high school based study conducted in Debar Markos of Northwest Ethiopia reported prevalence of performed and attempted rape at $8.8 \%$ and $11.5 \%$, respectively [10].

Sexual violence can lead to a wide variety of serious consequences, including behavioral and psychological problems, sexual dysfunction, relationship problems, low self-esteem, depression, thoughts of suicide, alcohol and substance abuse, and sexual risk taking [11]. Victim of sexual violence is susceptible to contracting HIV in childhood or adolescence, because of the increased likelihood of engaging in unprotected sex, having multiple partners such as commercial sex workers and those engaged in substance abuse [12]. While most research has focused on the direct trauma of sexual violence, survivors also struggle with the perceived harm to those close to them. This leads to a culture of silence about cases of sexual violence. The true picture about the scope and related consequences of sexual violence is concealed. However, sexual violence is one of the major public health problems in Ethiopia.

Moreover, of all dimensions sexual violence is not well studied in Ethiopia, especially among female students in preparatory schools [12]. The current study believed for boosting to the existing knowledge in giving attentions to the problems by the policy makers, programmers and academia and or researchers as well. Due to its geographical location and socio-demographic vulnerability, Modjo and Bishoftu towns were considered as one of the emerging risk collider's development where many mega project sites, commercial farm areas and development sites such as sugar plantation and construction sites are located with involving huge number of causal and seasonal mobile workers [13]. Female students in/around these towns are vulnerable to various health and related risks, including sexually transmitted infections including HIV and AIDS. Therefore, this study aimed to assess the prevalence of sexual violence and associated factors among female students in preparatory schools of Modjo and Bishoftu towns, East Showa zone, Oromia state, Ethiopia.

\section{Materials and Methods}

\subsection{Study Area/Setting}

The study was conducted in preparatory schools found in Modjo and Bishoftu towns in the East Showa Zone, Oromia Regional State. Modjo and Bishoftu towns are located at 72 $\mathrm{kms}$ and $49 \mathrm{kms}$ away from Addis Ababa (a capital of Ethiopia) along the road stretched from Addis Ababa to Djibouti. In the towns, there are many factories; common substance uses (Khat, tobacco and alcohol) houses, dry ports and highest investment companies. There are five preparatory schools found in the study area (two in Modjo town and three in Bishoftu town). Preparatory schools found in the two towns are surrounded by commercial farms, development sites such as sugar plantations and construction sites involving a huge number of casual or seasonal mobile workers.

\subsection{Study Design and Period}

School based cross sectional study design was conducted using both quantitative and qualitative data collection methods from September 1 to December 30, 2018.

\subsection{Population}

\subsubsection{Source Population}

All Female students registered for a preparatory class in Modjo and Bishoftu towns were the source population for the quantitative methods, while all women in the towns were the source population for qualitative study.

\subsubsection{Study Population}

All female students registered for a preparatory class in selected Modjo and Bishoftu preparatory schools in the academic year of 2018/2019 were the study population.

\subsubsection{Inclusion Criteria}

All female students registered and attend the preparatory class $\left(11^{\text {th }}\right.$ and $12^{\text {th }}$ grade) in selected Modjo and Bishoftu preparatory schools were included.

\subsubsection{Exclusion Criteria}

Those female students who were ill and unable to communicate during the study time were excluded.

\subsection{Sample Size Determination}

For the quantitative study, the single population proportion formula was computed using the assumptions of $25 \%$ of the expected prevalence rate of sexual violence among female students [9], 95\% confidence level $(\mathrm{Z} \alpha / 2=1.96), 5 \%$ of margin of error, design effect of 2 and $10 \%$ for possible nonresponse rate.

$$
\mathrm{n}=\frac{(\mathrm{Z} \alpha \div 2)^{2} \times \mathrm{P}(1-\mathrm{P})}{\mathrm{d}^{2}}=\frac{1.96^{2} \times 0.25 \times(1-0.25)}{0.05^{2}} \times 2+10 \%=323
$$

Where: $\mathrm{Z}(/ 2=$ the confidence limits of the survey result (critical value of $95 \% \mathrm{CI}=(1.96)$.

$\mathrm{P}=$ The proportion of study population experiencing sexual violence $=25 \%(0.25 \%)$.

$\mathrm{d}=$ The desired precision of the estimate (the margin of error between the sample and population $(2 \%))$, which mean $(0.05)$.

$\mathrm{n}=$ total sample size (323).

For the factors associated with sexual violence double population proportion formula was used to determine the sample size [12]. The sample size was calculated for some of the factors associated with sexual violence obtained from different literatures by using the StatCalc calculation of Epi Info statistical software version 7 as follows (Table 1). 
Table 1. Sample size calculation for the factors associated with sexual violence using different assumptions December 2018.

\begin{tabular}{llllll}
\hline Variable & CL & Power & $\begin{array}{l}\text { Ratio: unexposed: } \\
\text { exposed }\end{array}$ & $\begin{array}{l}\text { Odd } \\
\text { ratio }\end{array}$ & $\begin{array}{l}\text { Sample } \\
\text { size }\end{array}$ \\
\hline $\begin{array}{l}\text { Unwelcome } \\
\text { touching }\end{array}$ & $95 \%$ & $80 \%$ & 4.46 & 1.36 & 150 \\
$\begin{array}{l}\text { Faced forced } \\
\text { sexual } \\
\text { attempt }\end{array}$ & $95 \%$ & $80 \%$ & 4.93 & 1.79 & 80 \\
$\begin{array}{l}\text { Encountered } \\
\text { unwanted kiss }\end{array}$ & $95 \%$ & $80 \%$ & 3.2 & 2.41 & 31 \\
\hline
\end{tabular}

Hence, the sample size calculated for the prevalence was greater than the sample size calculated for the associated factors the largest calculated sample sizes (323) was taken to include in the study.

\subsection{Sampling Procedure}

For quantitative method, all the preparatory schools (four) and all sections in both towns were included into the study. Initially, registration books or attendance sheets were used as a sampling frame. The total sample was allocated proportionally to each grade based on the number of female students found in each of the sections. Finally, systematic random sampling was used to select study units from each section. In case a student was absent from school during the time of data collection, the next sampled student was taken (Figure 1).

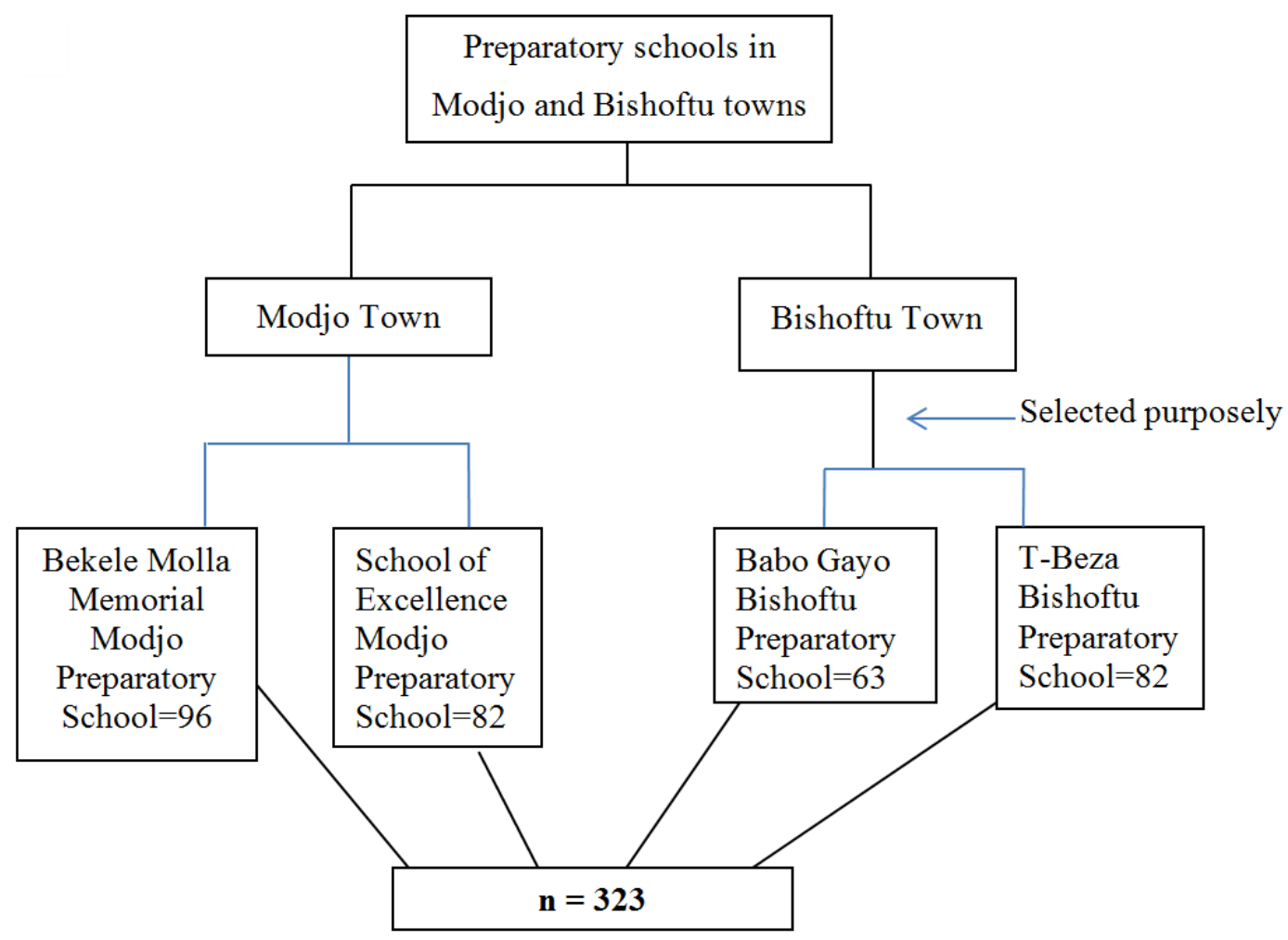

Figure 1. Sampling producer among female students of Preparatory schools in Modjo and Bishoftu towns, December 2018.

For the qualitative study, purposive sampling was used to select the discussants. The discussion was conducted using semi-structured, open-ended questions in order to provide the discussants more room for discussion of the complex issues of sexual violence and experiences of female students. Four Focus group discussions (FGD's) with a total of 38 discussants from women's community representatives were participated. Each FGD's consisted from 8-10 participants and the discussions were conducted until there was saturation of information/ending ideas.

\subsection{Data Collection Procedures}

\subsubsection{Quantitative Data}

Quantitative data was collected using self-administered questionnaires developed after reviewing different literatures. A number of questions that can address the objectives of the study were gathered from previous similar studies and other materials. The final version was translated into Afan Oromo (the regional working language) and again back to English by another person who has the same level of language capacity or fluent speaker of both languages to ensure its validity and consistency. In the process of data collection, both facilitators and supervisors were given a topic guideline prepared in the regional working language.

Data was collected using four trained data collectors and two supervisors who have public health and sociology backgrounds. Training was provided on the objective of the study, tools and data collection procedures.

The self-administered questionnaires were done when the selected students have a free period after discussing with the school principals. Each data collectors introduced themselves to selected respondents, explained the objectives of the study, and started after informed verbal consent was obtained from each study participant. To ensure the validity of the data, $10 \%$ of the questionnaires 
were randomly checked for completeness by supervisors and principal investigators.

\subsubsection{Oualitative Data}

The discussions were conducted using semi-structured, open-ended topic guides. The necessary protection was made to carry out the discussions in quiet places that were chosen by the participants so that they could discuss freely without being affected by the surrounding conditions. Trained supervisors moderated the discussion and the principal investigator facilitated the sessions. Each session was taperecorded and the principal investigator together with moderators transcribed and translated from the regional working language to English after each session from verbal description and field notes.

\subsection{Data Quality Control}

The quality of the data was assured through careful design, translation, providing proper training for data collectors and supervisors, pre-testing of the questionnaire (considering 5\% of the total sample size and appropriate modifications were made), close supervision during data collection and proper handling of the data. It was monitored frequently in the field and all collected questionnaires were examined for completeness and consistency during interview and at the end of each day. With regard to data management, all completed interview forms was reviewed and checked by supervisors. Forms with missing data or inconsistencies were returned to the interviewers for completeness and corrections.

To ensure the quality of the data, the data collectors, moderators and supervisors were professionals who had prior experience in both quantitative and qualitative data collection. Enough training was given to help data collectors and familiarize themselves with the tools and procedure to refresh their knowledge and skills in conducting quantitative research, facilitating FGDs, and on note taking during FGDs. The supervisors and the principal investigator checked all the data collection and oversee the overall data collection process.

Supervision during data collection was done to monitor how the data collectors are handling; FGD was conducted. Checking its completeness, accuracy, clarity, consistency and so on were done on a daily basis. Corrections of gaps were made, while still special care was given during data entry, and data cleaning was performed accordingly. The whole data was cross-checked for reliability and about $10 \%$ of data were double entered to check consistency of results before analysis.

\subsection{Operational Definitions}

Sexual Violence: Sexual violence is any sexual act, attempt to obtain a sexual act, sexual intercourse forcefully or by any means without her consent, facing unwelcome touch of sexual body part (e.g. Genitalia, breasts), harassment, Physical body harm, verbal jokes, threatening or other she didn't want to it that are intentionally done to girls. Therefore, when one of the above situations is encountered, it is considered as committed sexual violence.

\subsection{Data Processing and Analysis}

After data collection, each questionnaire was coded separately and quantitative data were entered into Epi Info version 7 and exported to SPSS software 20 version by the principal investigator and then after cleaning, and editing was done. Coding of different variables was also carried out before analysis. Descriptive statistics (frequency and percentage) were computed. Bivariate and multivariate analysis was used to examine the associations between the study variables. Differences were considered to be statistically significant when $P$ Value is $<0.05$ in all models. Logistic regression model was used to determine the Odds Ratio and 95\% confidence interval and describe the strength of association between the study variables by controlling for the effect of possible confounders and prediction of population parameters. Assumptions like normality of continuous variables and multi-collinearity of independent variables were checked to be satisfied using the appropriate methods.

For the FGD's, data analysis was done manually using excel and the texts were used to write summary report. The summary was written based on common codes arising from the pre-defined themes and was used to supplement the results and discussions of quantitative findings. Summarized themes were presented using quotation for further report writing. In this case, quotes from FGD's participants that illustrate key concepts were directly used during analysis of the data, and the concepts were developed into major themes emerged under each discussion guide. The result were triangulated with quantitative findings and fitness and relevance of thematic areas was tested by constant comparison.

\subsection{Ethics Considerations}

Ethical approval and clearance were obtained from an Ethical committee of Research and Publication office of Public Health Department, Adama Hospital Medical College. In addition, the official letter was written to concerned local education administrators by an institutional Review Board (IRB) of the college. Principal investigator submitted an official letter to them, permission and consent were obtained from the two towns Education office, and in turn, the Education offices of the two towns were officially wrote the support letters to their selected preparatory schools in their towns. Introduction of the study, method of the questioning and confidentiality letter was attached to the cover page of the questionnaires.

Informed consent was obtained from each study participant after presenting the detailed explanation of benefits and harm of the study. There is no invasive procedure in this study, however, study participants was clearly orientated about the purpose and usefulness of the study and thereby creating a friendly atmosphere to reduce their stress as the study touches sensitive privacy issues. Moreover, before administering the questionnaires, participants were informed about their full rights to agree or disagree to participate in the study and they were told for the possibility of withdrawing at any time during filling the questionnaire. 


\section{Results}

\subsection{Socio-Demographic Characteristics}

A total of 323 female students of preparatory schools in Modjo and Bishoftu towns was planned and participated in the study making a response rate of $100 \%$. The majority 232 $(72.3 \%)$ of the respondents were between 17 to 18 years of age. The mean (+SD) age of the respondent was 17.83 $(+1.07)$ years, ranging from 11-21 years.

Regarding their religion, the majority of the $218(67.5 \%)$ were orthodox, while $79(24.5 \%)$, and $16(5 \%)$ were protestant, catholic and Muslim, respectively. The study participants were predominantly Oromo, $168(52.7 \%)$ followed by Amhara that accounted for 96 (30.1\%). Most of the study participants, 227 (70.3\%) were grown up in urban (their childhood residence where they live longest time before age 12). More than half $(53.3 \%)$ of the study participants were attending grade 12 .

Regarding the family history, most $(71.5 \%)$ of the parents of study participants was currently separated and they were not living together, due to divorce. And they reported that, $103(31.9 \%)$ of their parents were completed grade 12 and above, while 48 (14.9\%), 64 (19.8\%), and 89 (27.6\%) were not having a formal education, completed grades 1-8 and completed grade $9-12$, respectively.

Concerning respondents' way of life, most (56.7\%) of the study participants was ever lived away from their one or both biological parents. More than half (51.1\%) of the study participants did not have a boyfriend or male partner at the time of the study, while about $158(48.9 \%)$ were married or lived with their male partner (Table 2).

Table 2. Socio-Demographic characteristics of female students of preparatory schools in Modjo and Bishoftu towns, December 2018.

\begin{tabular}{|c|c|c|c|}
\hline Variable & Response category & Number & Percent \\
\hline \multirow{3}{*}{ Age in years } & $<17$ & 23 & 7.2 \\
\hline & $17-18$ & 232 & 72.3 \\
\hline & $>19$ & 66 & 20.5 \\
\hline \multirow{4}{*}{ Religion } & Orthodox & 218 & 67.5 \\
\hline & Protestant \& catholic & 79 & 24.5 \\
\hline & Muslim & 16 & 5.0 \\
\hline & Others* & 10 & 3.0 \\
\hline \multirow[t]{2}{*}{ Ethnicity } & Amhara & 96 & 30.1 \\
\hline & Others** & 55 & 17.2 \\
\hline \multirow{2}{*}{ Childhood residence } & Urban & 227 & 70.3 \\
\hline & Rural & 96 & 29.7 \\
\hline \multirow{2}{*}{ Grade level } & Grade 11 & 151 & 46.7 \\
\hline & Grade 12 & 172 & 53.3 \\
\hline Parents living together currently & Yes & 92 & 28.5 \\
\hline \multirow{5}{*}{ Educational status of family } & Not have formal education & 48 & 14.9 \\
\hline & Completed grade $1-8$ & 64 & 19.8 \\
\hline & Completed grade 9-12 & 89 & 27.6 \\
\hline & Completed above grade 12 & 103 & 31.9 \\
\hline & I don't know & 19 & 5.9 \\
\hline \multirow{2}{*}{ Ever lived away from biological parents } & No & 140 & 43.3 \\
\hline & Yes & 183 & 56.7 \\
\hline \multirow{2}{*}{ Ever had a boyfriend, married or lived with a male partner } & No & 165 & 51.1 \\
\hline & Yes & 158 & 48.9 \\
\hline
\end{tabular}

NB. Others include: *wakefata etc. **Gurage, Kambata, Tigre and wolayita.

\subsection{Behavioral and Environmental Characteristics}

Respondents were asked about their behavior, whether they had multiple sexual partners or ever involved in any substance use. From the study participants, 8 (2.5\%) reported to have multiple sexual partners. More than seven in ten $(70.6 \%)$ of participants practiced Khat chewing, alcohol use, smoking cigarette, and using Hashish or Shisha. Respondents were also asked whether they lived around commercial areas of substance abuse and whether this ever influenced them, or their peers influenced their exposure to sexual violence. About 207 (64.1\%) of the participants ever lived around commercial areas of substance use, whereas, $218(67.5 \%)$ of the respondents were ever been influenced by their peers to have sexual exposure with male partners to have sexual intercourse (Table 3).

Table 3. Behavioral and environmental characteristics of female students of preparatory schools in Modjo and Bishoftu towns, December 2018.

\begin{tabular}{|c|c|c|c|}
\hline Variable & Response category & Number & Percent \\
\hline \multirow{2}{*}{ Ever had multiple sexual partners } & No & 315 & 97.5 \\
\hline & Yes & 8 & 2.5 \\
\hline \multirow{2}{*}{ Ever involved/addicted to any substance use } & No & 95 & 29.4 \\
\hline & Yes & 228 & 70.6 \\
\hline \multirow{2}{*}{ Ever influenced by peers to have sexual exposure with males } & No & 218 & 67.5 \\
\hline & Yes & 105 & 32.5 \\
\hline Ever lived around chat chewing houses, Shisha houses, alcohol drinking houses & No & 116 & 35.9 \\
\hline
\end{tabular}




\subsection{Prevalence and Forms of Sexual Violence}

Among the study participants, 123 (38.9\%) of them ever faced an unwelcome touching on their breasts or genitals, harassment, and verbal jokes without their consent. Most of the participants, $221(68.4 \%)$ ever had sexual intercourse forcefully or by any means without their consent and they had sex through threats of harm, forced to have drug and by deception. Eventually, the majorities, 239 (74\%) of the respondents ever had faced sexual violence in the form of either unwelcome touching; verbal jokes or had forceful sexual intercourse by any means without their consents. The study found that the overall prevalence of sexual violence among study participants was $74 \%$. Regarding the perpetrators, the vast majorities, $278(86.1 \%)$ were their boyfriends, while $19(5.9 \%)$ and $26(8.0 \%)$ were their teachers and others (schoolboys, relatives and strangers), respectively.

The study also assessed the place where sexual violence happened and most of the respondents, 279 (90.3\%) had exposed in Hotels, victim's homes, perpetrators' homes, school or in the bushes. Most of respondents, $279(86.4 \%)$ did not report their incidents to anyone including their families. Only $44(13.6 \%)$ respondents ever reported about the incident, they reported to the police, health institutions, and school officials or to their family and friends. Among those who never reported the incident, 280 (86.7\%) ascribed their silence to their perception that the legal bodies do not helpful, while $43(13.3 \%)$ ascribed it to fear of parents, humiliations, or threatened by the perpetrators.

Concerning the consequences of sexual violence, particularly health and health related outcomes had exposed the respondents to different reproductive health issues and psychological problems. Most of the respondents, 279 $(86.4 \%)$ were exposed to unintended pregnancy and unsafe abortions. In addition, some of them, 25 (7.7\%) faced serious psychological problems like fear, anxiety, blaming others for the incident, self-hate, and suicidal ideations. In addition, about $19(5.9 \%)$ were exposed to genital ulcer/vaginal discharge, too much bleeding, acquired infectious disease like STI or HIV (Table 4).

Table 4. Prevalence of sexual violence of female students of preparatory schools in Modjo and Bishoftu towns, December 2018.

\begin{tabular}{|c|c|c|c|}
\hline Variable & Response category & Number & Percent \\
\hline \multirow{2}{*}{ Ever faced unwelcome touching } & No & 200 & 61.9 \\
\hline & Yes & 123 & 38.9 \\
\hline \multirow{2}{*}{ Ever had sexual intercourse forcefully or by any means without consent } & No & 102 & 31.6 \\
\hline & Yes & 221 & 68.4 \\
\hline \multirow{2}{*}{ Sexual violence } & No & 84 & 26 \\
\hline & Yes & 239 & 74 \\
\hline \multirow[t]{2}{*}{ Perpetrator of sexual violence } & Teachers & 19 & 5.9 \\
\hline & Others*** & 26 & 8 \\
\hline \multirow{2}{*}{ Place of sexual violence happened } & Hotel & 279 & 90.3 \\
\hline & Other places $* * * *$ & 30 & 9.7 \\
\hline \multirow{2}{*}{ Reporting status of a violent incident } & Not reported & 279 & 86.4 \\
\hline & Reported & 44 & 13.6 \\
\hline Reason for not reported & Thought legal body not helpful & 280 & 86.7 \\
\hline \multirow{3}{*}{ Consequence of sexual violence } & Pregnancy/abortion & 279 & 86.4 \\
\hline & Psychological problem & 25 & 7.7 \\
\hline & Others $* * * * * *$ & 19 & 5.9 \\
\hline \multirow{2}{*}{ Know who ever encountered sexual violence } & No & 149 & 46.1 \\
\hline & Yes & 174 & 53.9 \\
\hline
\end{tabular}

NB: others include: $* * *$ school boy, relatives, strangers.

****her home, his home, school, in the bush.

*****Afraid of parents, Humiliation, threated by rapist.

$* * * * * *$ too much bleeding, genital discharge, acquired STI, HIV.

From the results of GDs, almost all discussants agreed that boyfriends, teachers, schoolboys, relatives, strangers and neighbors were found to be participating in sexual violence as they have seen in their community. They also witnessed that their children faced sexual violence and they heard from different media outlets. For instance, a woman (42 years women from community representatives) reported on actual sexual violence as follows:

"She has seen old men, teachers, boyfriends and strangers in the local community who violated female students, young girls, and old women. She has known preparatory teacher, who had sexual intercourse forcefully with a female student, who was a 17 year old girl. Finally, she observed the girl who became pregnant and this was told to the girl's family, and the girl underwent unsafe abortion".

Most of the discussants further mentioned major consequences of sexual violence such as, STI, HIV/AIDS, unintended pregnancy, abortion, moral depression, disruption from their schooling, attempting suicide, physical trauma, 
prostitution, disappearing from the family or community etc. For example, one woman reported on her personal sexual violence and outcomes:

“.... She has seen her relative who had sexual intercourse forcefully. The girl was a 16 years old and attending grade 11, whom she was abused by her boyfriend. After the incident, the girls experienced excessive bleeding, which resulted in depression and attempted suicide and disappearance from the family and friends. Because of the unintended pregnancy, the girl dropped out of school" (48 years women from religious representative)".

\subsection{Factors Associated with Sexual Violence}

At the bivariate level, age, parent education, Perpetrator category, living around chat area and ever knows sexually violated women were factors significantly associated with sexual violence $(\mathrm{P}<0.05)$. However, aafter adjusting for different variables in the model, the following variables were significantly associated with sexual violence: age, perpetrator category and those who knew a woman encountered sexual violence $(\mathrm{P}<0.05)$. Accordingly, respondents 17 and less age were more than six (AOR, 6.39; 95\%CI: 3.64, 63.12) times more likely to have sexual violence compared to those 19 years and above. Those respondents who reported to have a perpetrators of teacher and another like stranger, relatives were less (AOR, 0.37; 95\%CI: 0.01, 0.13) and (AOR, 0.36; $95 \% \mathrm{CI}: 0.01,0.11)$ likely to have sexual violence, respectively, compared to those whose perpetrators are their own boyfriends. Also, those respondents who ever knew other women who ever encountered sexual violence were more likely (AOR, $1.21 ; 95 \% \mathrm{CI}: 1.13,4.59)$ to have sexual violence compared to their counterparts (Table 5).

Table 5. Factors associated with sexual violence among female students of preparatory schools in Modjo and Bishoftu towns, December 2018.

\begin{tabular}{|c|c|c|c|c|}
\hline \multirow{2}{*}{ Variable } & \multicolumn{2}{|c|}{ Sexual violence } & \multirow{2}{*}{ COR (95\% CI) } & \multirow{2}{*}{$\operatorname{AOR}(95 \%$ CI) } \\
\hline & No $(\%)$ & Yes $(\%)$ & & \\
\hline \multicolumn{5}{|l|}{ Age in years } \\
\hline$<17$ & $1(4.3)$ & $22(95.7)$ & $12.57(1.59,99.21)^{*}$ & $6.39(3.64,63.12)^{*}$ \\
\hline $17-18$ & $58(25.0)$ & $174(95.0)$ & $1.71(0.96,3.07)$ & $1.26(0,55,2.89)$ \\
\hline$>19$ & $24(36.4)$ & $42(63.6)$ & $1: 00$ & $1: 00$ \\
\hline \multicolumn{5}{|l|}{ Parent education status } \\
\hline No formal education & $17(35.4)$ & $31(64.6)$ & $1: 00$ & $1: 00$ \\
\hline Completed grade 1-8 & $12(18.8)$ & $52(81.2)$ & $2.38(1.00,5.63)^{*}$ & $3.32(0.96,11.47)$ \\
\hline Completed grade 9-12 & $21(23.6)$ & $681(76.4)$ & $1: 78(0.82,3.83)$ & $1.97(0.63,6.08)$ \\
\hline Completed $12^{\text {th }} \&$ above & $25(24.3)$ & $78(75.7)$ & $1.71(0.81,3.60)$ & \\
\hline Don’t know & $9(47.4)$ & $10(52.6)$ & $0: 61(0.21,1.79)$ & $1.37(0.44,4.26)$ \\
\hline \multicolumn{5}{|c|}{ Every lived away from biological parents } \\
\hline No & $46(32.9)$ & $94(67.1)$ & $0.54(0.32,0.86)^{*}$ & $0.74(0.34,1.58)$ \\
\hline Yes & $38(20.8)$ & $145(79.2)$ & $1: 00$ & $1: 00$ \\
\hline \multicolumn{5}{|l|}{ Perpetrator category } \\
\hline Boyfriend & $46(16.5)$ & $232(83.5)$ & $1: 00$ & $1: 00$ \\
\hline Teacher & $16(84.2)$ & $3(15.8)$ & $0.04(0.01,0.13)^{*}$ & $0.37(0.01,0.13)^{*}$ \\
\hline Others $\infty$ & $22(84.6)$ & $4(15.4)$ & $1.04(0.01,0.11)^{*}$ & $0.36(0.01,0.11)^{*}$ \\
\hline \multicolumn{5}{|c|}{ Ever influenced by peers to have sexual exposure to male } \\
\hline No & $40(18.3)$ & $178(81.7)$ & $1: 00$ & $1: 00$ \\
\hline Yes & $44(41.9)$ & $61(58.1)$ & $0.31(0.19,0.52)^{*}$ & $0.55(0.26,1.16)$ \\
\hline \multicolumn{5}{|l|}{ Place of sexual violence } \\
\hline Hotel & $46(16.5)$ & $233(83.5)$ & $1: 00$ & $1: 00$ \\
\hline Others $\infty \infty$ & $27(90.0)$ & $3(10.0)$ & $0.02(0.01,0.08)^{*}$ & $0.00(0.001,1.009)$ \\
\hline \multicolumn{5}{|c|}{ Ever lived around Khat chewing, house } \\
\hline No & $45(38.8)$ & $71(61.2)$ & $1: 00$ & $1: 00$ \\
\hline Yes & $39(18.8)$ & $168(81.2)$ & $2.73(1.64,4.53) * * *$ & $1.90(0.92,3.91)$ \\
\hline \multicolumn{5}{|c|}{ Know who ever encountered Sexual Violence } \\
\hline No & $51(34.2)$ & $98(65.8)$ & $1: 00$ & $1: 00$ \\
\hline Yes & $33(19.0)$ & $141(81.0)$ & $2.22(1.33,3.69)^{*}$ & $1.21(1.13,4.59)^{*}$ \\
\hline
\end{tabular}

NB: COR: Crude Odds Ration AOR: Adjusted Odds Ration $* \mathrm{P}<0.05 * * \mathrm{P}<0.01 * * * \mathrm{P}<0.001$.

Note: variables not entered into the model because they were not found significant in bivariate analyses.

Others includ: $\infty$ stranger, relatives $\infty \infty-b u s h$, school, home.

\section{Discussions}

This study used a cross-sectional study design to assess the prevalence of sexual violence among preparatory school female students in Modjo and Bishoftu towns. This study found that the overall prevalence of sexual violence either unwelcome touching or verbal jokes or forceful sexual intercourse among study participants was 74\%. Type of perpetrators and ever known sexual violated women were important factors significantly associated with sexual violence.
Among 323 female students who participated in the study, a total of $74 \%$ study participants was experienced sexual violence either unwelcome touching or verbal joking or forceful sexual intercourse during their lifetime. This figure is more than the level reported in the study conducted in Nepal showing 46\%, [1] and in Greece, 46\% [14]. The finding of this study is also more prevalent than the finding from Nigeria University study, which reported 46.7\% [15]. These variations might be due to differences in methods and differences in the socio-demographic, behavioral and environmental characteristics of the study populations. 
Other African studies dealing with sexual violence from Nigeria and Uganda universities, 23.5\% [16] and 33\% [17] respectively, were all less prevalent than the sexual violence in the present study. Our prevalence was also higher than the figures reported from Cameroun, 16\% [18] and Sierra Leone, $23 \%$ [19]. This difference might be due to the definitions used for sexual violence. In the current study the definition for Sexual Violence is more inclusive than most of the other studies. However, the finding is lower than the study conducted in the Ambo University among female students that showed the prevalence of sexual violence in their lifetime of $76.4 \%$ [20]. This difference is minimal, but it might reflect the variations in socioeconomic and-cultural contexts between the study populations or it might be the setting and a population difference.

Our study participants who were sexually violated, 123 (38.9\%) included all who ever faced an unwelcome touching sexually like breasts, genitals, harassment, verbal jokes and other actions without their consents. Most of them, 221 $(68.4 \%)$ ever had sexual intercourse forcefully or by any means without their consent while few of them, $102(31.6 \%)$ did not have sexual intercourse.

The study findings were also higher than the study done in Harar town of Eastern Ethiopia showed a prevalence of $25 \%$ among female high school students, which was taken as the proportion of the study population experiencing sexual violence for the current study. According to the previous study, students used addictive drugs like alcohol (18\%), Khat and Shish (7.2) [21]. Female high school students who reported high risk of sexual violence faced unwelcome touching of body part and forced sexual attempt, in spite of having boyfriend. The violation was associated with alcohol consumption. This is also due to differences in methods and differences in the socio-demographic, behavioral and environmental characteristics of the study populations.

On the other hand, qualitative part of this study shows us, sexual violence can lead to a wide variety of health and health related consequences, including behavioral and psychological problems, sexual dysfunctions, relationship problems, low self-esteem, depression, fear, suicidal tendency, alcohol and substance abuse and sexual risk taking. Being a victim of sexual violence and being susceptible to HIV share a number of risk behaviors. Forced sex in childhood or adolescence, for instance, increases the likelihood of engaging in unprotected sex, having multiple partners, commercial sex work, and substance abuse. However, a culture of silence surrounds cases of violence against women making it difficult to get a true picture of its scope and related consequences.

Also from the results of qualitative method, discussants strongly expressed their concern and pointed out the need of responsible stakeholders to take steps to regulate sexual violence and conduct promotions against substance use like Khat chewing, alcohol and drugs, especially in the school environments. Further action to change behavior among young girls and boys need special attention by the community, responsible government bodies and families. Discussants also expressed their concern about young girls and boys getting out of control in their behavioral norms of the general population. For example, a woman discussant was angered by the prevalent ill behavior perpetrated against our girls in school and out of school as follows:

"When unwelcome touching and harassment of our girls happens more and more in our schools it constitutes potentially significant barriers to gender equality and limit the ability of female students' participation in school education and this is unacceptable both by the Government and the community. She highly emphasized the need of awareness creation, strong controlling mechanism, and appropriate punishment of perpetrators of sexual violence through the rule of law" (a 36 year old woman)".

In the current study, being younger age is associated with sexual violence and this supporting the notions from different studies. According to $\mathrm{CDC}, 80 \%$ of female victims were raped before they turned 25 years of age, and almost half were raped before they were 18 years [20]. Similar studies in U.S showed that, college aged females between 18-24 years old experienced higher rates of sexual violence compared to other age groups [21].

Boyfriends are the most perpetrators of sexual violence in the current study supporting another study conducted in Ethiopia reveals students who reported to have a boyfriend were found to be five times at a higher risk of experiencing sexual violence since being admitted to the university than those who did not have a boyfriend [22]. Respondents who know someone having a history of sexual violence were more likely to report the incident compared to their counterparts. This could be attributed to report their experiences as they are more familiar with the issues.

\section{Limitation of the Study}

The study has come up with some limitations and would like to inform others who may use this finding as a baseline for their consideration. Error inherent in the method of data collection due to self-administered questionnaire, and this may have made known to miss-understanding of the questions. The prevalence of sexual violence may be underreported due to the sensitivity of the subject. There might be a recall bias or a social desirability effect as the study participant's recall their experiences related to sexual violence in the last time. In addition, the study used a crosssectional study design for which it might not show the causeeffect relationship between the study variables.

\section{Conclusions}

In conclusion, this study shows $74 \%$ of study respondents had ever experienced sexual violence, which reveals a very high prevalence in the study area. The main experiences have been either ever faced unwelcome touching or verbal jokes and ever had sexual intercourse without their consents. Age, types of perpetrators and respondents who ever heard of women who sexually violated were factors significantly associated with sexual violence among the study participants. 


\section{Recommendations}

Based on the current study results it is possible to recommend that there is a need to have systematic and strategic intervention at school and community based programs to address the full context of young girls and women's lives including society, behavioral and environmental factors leading to these problems. Institutions like high schools and preparatory schools found in Modjo and Bishoftu towns should work towards minimizing the risk of sexual violence by implementing strategies like life skills education, peer education and strengthening youth friendly services targeting through different outlets. In addition, concerned bodies found in the study areas should work on designing and implementing targeted environmental, behavioral and social factors promoting sexual violence, particularly among female students and others young girls through the involvement of different stakeholders using a multi-sectorial approach.

Moreover, the education office and other stakeholders found in the study areas should build strong policy and strategy for putting legal actions into practice by taking appropriate and educative measures on the perpetrators, particularly focusing on teachers and boyfriends. Strengthening and expanding programs providing information, education, behaviour change and communication activities and messages aimed at preventing sexual violence at school level as well as in the community level are needed.

\section{Authors' Contributions}

Conception of the work, data collection, analysis, interpretation and drafting the article were done by all authors. Critical revision of the article and final approval of the version to be published was also performed by all the authors.

\section{Competing Interests}

All authors have declared that they have no competing interests in this paper.

\section{Consent of the Publication}

We do not have any conflict of interest for publication

\section{Availability of Data and Materials}

The data which we have used in this paper is taken from the survey conducted for the interest of this report and can be available on request.

\section{Acknowledgements}

We are very much grateful to the Adama Hospital Medical College for supporting and facilitated the study. The study interviewees are appreciated for their willingness to participate in the research.

\section{References}

[1] Lamichhane P, Puri M, Tamang J, Dulal B 2011. Women's status and violence against young Married women in rural Nepal. BMC Womens Health. BMC Womens Health. 2011 (25) 11: 19. doi: 10.1186/1472-6874-11-19. Available at: https://www.ncbi.nlm.nih.gov/pubmed/21612603.

[2] World Health Organization. 2005. WHO Multi-Country Study on Women's Health and Domestic Violence against Women. WHO, Geneva. Available at: https://www.who.int/gender/violence/who_multicountry_stud y/summary_report/summary_report_English2.pdf.

[3] Bekele AB, Bekele D, Van Aken MA, Dubas JS, Sexual Violence Victimization Among Female Secondary School Students in Eastern Ethiopia, 2011. Available at: https://www.ncbi.nlm.nih.gov/pubmed/22145540.

[4] Heise L, Ellsberg M, Gottmoeller M: A global overview of gender based violence. International Journal of Gynecology and Obstetrics. 2002, 78 (Supp 1): S5-S14.

[5] WHO. Global estimates of health consequences due to violence against children. Background paper to the UN Secretary General's study on violence against children. Switzerland: World Health Organization, 2006. Available at: https://www.unicef.org/violencestudy/.../Study\%20on\%20Viol ence_Child-friendly.pdfd.

[6] Jewkes R, Vundule C, Maforah F, Jordaan E. Relationship dynamics and adolescent pregnancy in South Africa. Soc Sci Med 2001. Available at: https://www.ncbi.nlm.nih.gov/pubmed/11218177.

[7] Matasha E, Ntembelea T, Mayaud P, et al. Sexual and reproductive health among primary and secondary school pupils in Mwanza, Tanzania, 1998. Available at: https://www.ncbi.nlm.nih.gov/pubmed/9828954.

[8] Jote Markos Cafo, Agumassie Semahegn Demisie, Balcha Berhanu Abera 2014. Assessment of Sexual Violence and Associated Factors among High School Students in Harari Regional State, Harar Town, Eastern Ethiopia. Available at: https://www.researchgate.net/.../320708089_Assessment_of_s exual_violence_and_associ.

[9] Desalegn Tarekegn, Balcha Berhanu \& Yigrem Ali 2015, Prevalence and Associated Factors of Sexual Violence among High School Female Students in Dilla Town, SNNPR, Ethiopia. Available at: https://www.omicsonline.org/.../prevalence-andassociated-factors-of-sexual-violence.

[10] Mulugeta E, Kassaye M, and Berhane Y. Prevalence and outcome of sexual violence among high school students in Addis Ababa and western Showa: Ethiopia 1995. Available at: https://www.researchgate.net/.../11079472_Sexual_violence_a mong_female_high_scho.

[11] Worku A, and. Addisie M. Sexual Violence among female High school students in Debark, Northwest Ethiopia: East African medical Journal, 1 96-99 2002. Available at: https://www.ajol.info/index.php/eamj/article/view/8911.

[12] Seblework T, Ahmed A. and Negussie, D 2004. Assessments of sexual coercion among Addis Ababa University female students Addis Ababa University, Ethiopia. Available at: etd.aau.edu.et/bitstream/handle/123456789/12270/Seblework \%20Tadesse.pdf. 
[13] Federal HIV/AIDS Program Coordination office (FHAPCO) Situational analysis of Adolescent HIV/AIDS and Related Interventions to Improve the Adolescent Component of the National HIV Program in Ethiopia, April, 2017. Available at: https://ethiopia.unfpa.org/.../HIV\%20Prevention\%20in\%20Et hiopia\%20National $\% 20$.

[14] Chan K et al. 2008: Psychological distress, anxiety and depression among nursing students in Greece. Available at: https://www.researchgate.net/.../47374416_Psychological_dist ress_anxiety_and_depre.

[15] Margaret-Mary, MMI, and Mezie-Okoye and Folusho F, Alamina, 2014: Sexual Violence among Female Undergraduates in a Tertiary Institution in Port Harcourt: Prevalence, Pattern, Determinants and Health Consequences. Available https://www.researchgate.net/.../273002517_Sexual_Violence _among_Female_Undergr.

[16] Iliyasu Z, Abubakar IS, Aliyu MH, Galadanci HS, Salihu HM. Prevalence and correlates of gender-based violence among female university students in Northern Nigeria. Afr J Reprod Health. 2011 Sep; 15 (3): 111-9. Available at: https://www.ncbi.nlm.nih.gov/pubmed/22574498.

[17] Agardh A, Odberg-Pettersson K, Ostergren PO: Experience of sexual coercion and risky sexual behavior among Ugandan university students. BMC Public Health. 2011 Jul 4; 11: 527. Available https://www.ncbi.nlm.nih.gov/pubmed/21726433.
[18] Menick D, 2002: Child sexual abuse in schools in Cameroon: Results of a survey-action program in Yaounde. Available at: https://www.researchgate.net/.../11334958_Child sexual abus e_in_schools_in_Cameroo.

[19] Alexander Y, 2010): The Prevalence of Sexual Violence among Female Refugees in Complex Humanitarian Emergencies: a Systematic Review and Meta-analysis. Available https:/www.ncbi.nlm.nih.gov/pmc/articles/PMC4012695/.

[20] Bekele, Deressa 2014): Experience of Sexual Coercion and Associated Factors among Female Students of Ambo University in Ethiopia. Available at: https://www.semanticscholar.org/.../Experience-of-SexualCoercion-and-Associated-amo.

[21] Jote Markos Cafo, Agumassie Semahegn Demisie, Balcha Berhanu Abera 2014. Assessment of Sexual Violence and Associated Factors among High School Students in Harari Regional State, Harar Town, Eastern Ethiopia. Available at: article.sciencepublishinggroup.com/pdf/10.11648.j.sr.2014020 5.12.pdf.

[22] Linkindoki S. Addressing the links between Gender-Based Violence and HIV in the Great Lakes region. Available at: http://www.unesco.org/new/fileadmin/MULTIMEDIA/HQ/BS P/GENDER/PDF/HIVGBVTanzania.pdf. 